\title{
Monitoring of the Operating Parameters a Low- Temperature Fuel-Cell Stack for Applications in Unmanned Aerial Vehicles: Part II
}

\author{
Magdalena Dudek $^{1,2 *}$, Andrzej Raźniak ${ }^{1,2}$, Bartlomiej Lis ${ }^{1,2}$, Tomasz Siwek ${ }^{1,3}$, \\ Bartosz Adamczyk ${ }^{1}$, Dagmara $\mathrm{Uh}^{3}$, Wojciech Kalawa ${ }^{1}$, and Tadeusz Uhl ${ }^{2,3,4}$, \\ ${ }^{1}$ AGH University of Science and Technology, Faculty of Energy and Fuels, al. A. Mickiewicza 30, \\ 30-059 Kraków, Poland \\ ${ }^{2}$ AGH University of Science and Technology, Center of Energy, str. Czarnowiejska 36, \\ 30-059 Kraków, Poland \\ ${ }^{3}$ UAVS Poland Sp. z o.o. \\ ${ }^{4}$ AGH University of Science and Technology, Faculty of Mechanical Engineering and Robotics, \\ al. A. Mickiewicza 30, 30-059 Kraków, Poland
}

\begin{abstract}
The second part of the paper is aimed at the analysis of hydrogen fuel demand for the operation of a PEMFC stack. The methodology of hydrogen utilisation for the production of electrical energy and for purging (purification processes) is presented. Based on the laboratory data derived from the electrical and non-electrical parameters recorded in this part of the paper, the design of the monitoring and control system of stack performance was elaborated and the implementation of the system tested. This solution enables not only the monitoring and control of electrical parameters, temperature, and humidity, but also management of the degree of humidification of PEMFC membranes using a short-circuit unit.
\end{abstract}

\section{Introduction}

The storage of sufficient amounts of hydrogen is one of the most challenging tasks along the path to the introduction and establishment of hydrogen as an alternative fuel. The use of hydrogen as an automotive and aviation fuel requires storage systems characterised by inherent safety as well as volumetric and gravimetric efficiency. Hydrogen can be stored as compressed gas (high-pressure storage) in gas cylinders, in solid materials (metal hydrides), and in chemical form (methanol, ethanol) [1-3]. Compressed hydrogen storage in gaseous form in composite vessels is the method most frequently applied to supplying protonexchange membrane fuel cells (PEMFCs) used to drive electrical engines for drones. In many EU countries, as well as around the world, hydrogen is compressed within a pressure range of 300-350 bar, enabling composite vessels of gaseous hydrogen to be filled within a short time. A composite pressure vessel normally consists of composite reinforcing, lining, and protective layers. Thanks to constant advances in technology, the role played by

* Corresponding author: potoczek@agh.edu.pl 
lightweight design and lightweight materials is becoming more and more important in the field of drones as well as in aerospace applications. The main important parameters for the selection of a type of composite vessel for hydrogen storage are gravimetric and volumetric, along with those concerned with cost efficiency. Nowadays, two main groups of composite cylinders designed for compressed hydrogen storage for drone applications can be found on the commercial market. The difference involves the type of lining layer (metal or plastic) used to manufacture the carbon fibres in composite tanks for the regulation of pressure in two steps, from high pressure (300-350 bar) to the range (0.5-1 bar) required for supplying a PEMFC stack [4-6].

Metal hydrides are another common way of storing hydrogen. Two categories of hydrides can be applied in this technology. The first comprises hydrides created through gas-solid chemical processes in reversible reactions:

$$
\mathrm{M}+0.5 \mathrm{xH}_{2} \leftrightarrow \mathrm{MHx}+\text { heat }
$$

At lower temperatures, the balance of reaction (1) is transferred to the right. The release of hydrogen is based on lowering the pressure in the tank (a direct result of its use) through constant feeding of heat throughout the period of gas intake. Hydrogen creates hydrides with a wide range of metals and metal alloys. These compounds may include metallic, ionic, or covalent bonds, or superpositions of these bonds. Only materials with the ability to absorb and release $\mathrm{H}_{2}$ within a temperature range of $0-100{ }^{\circ} \mathrm{C}$ under pressures between 1 and 10 bar can store hydrogen, with the process itself taking up to 5 minutes for a standard tank [7-9].

Hydrides of the second type release gaseous hydrogen in a reaction with water. An example of such a reaction with sodium borohydride is presented below:

$$
\mathrm{NaBH}_{4}+2 \mathrm{H}_{2} \mathrm{O} \rightarrow \mathrm{NaBO}_{2}+4 \mathrm{H}_{2}+\text { heat }
$$

$\mathrm{NaBH}_{4}$ is stored as an aqueous solution. Hydrogen is generated via the chemical reaction of hydrolysis, using a catalyst. $\mathrm{NaBH}_{4}$, characterised by relatively high hydrogen content $(10.8 \%)$, is stable and environmentally friendly. Moreover, it can be used to obtain pure hydrogen. Gaseous hydrogen is the only product of the hydrolysis reaction; the byproduct, $\mathrm{NaBO}_{2}$, can be recycled as $\mathrm{NaBH}_{4}$ through the absorption of hydrogen. The hydrolysis reaction is initiated at room temperature and does not require an external heat supply, since the reaction is exothermic [10-13]. A compact hydrogen system for supplying a PEMFC stack, in which humidified hydrogen is supplied to the stack, can be easily installed in a UAV.

The goal of this study was to carry out an analysis of hydrogen fuel demand and fuel utilisation during the operation of a PEMFC stack, as well as to develop assumptions for the elaboration of a system of management and control for energy distribution in the stack.

\section{Experimental}

\subsection{Analysis of hydrogen fuel demand for operation in a PEMFC stack}

An important factor in arriving at an initial estimate of the operating time of a PEMFC stack is determination of the amount of hydrogen fuel consumed during operation of the device at the so-called working point $(\mathrm{U}, \mathrm{I})$ corresponding to the nominal power $\mathrm{P}_{\text {nom. }}$.

Fig. 1 shows the predicted hydrogen fuel consumption (expressed in litres/min) for a family of PEMFC stacks operating within a range of specified $\mathrm{P}_{\text {nom }}$ of 200-5000 W. The relationship between the variations in hydrogen fuel required $\left(\mathrm{H}_{2}\right.$, litre/min) and the electric 
power $\mathrm{P}_{\text {nom }}$ produced by the family of PEMFC stacks is based on available technical data [56].

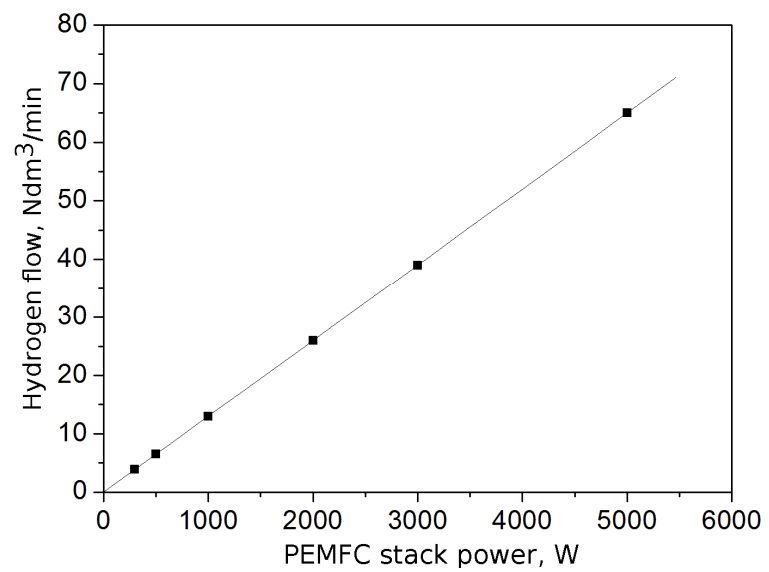

Fig. 1. Variations in required hydrogen fuel flow vs predicted nominal power $P_{n o m}$ of a PEMFC stack

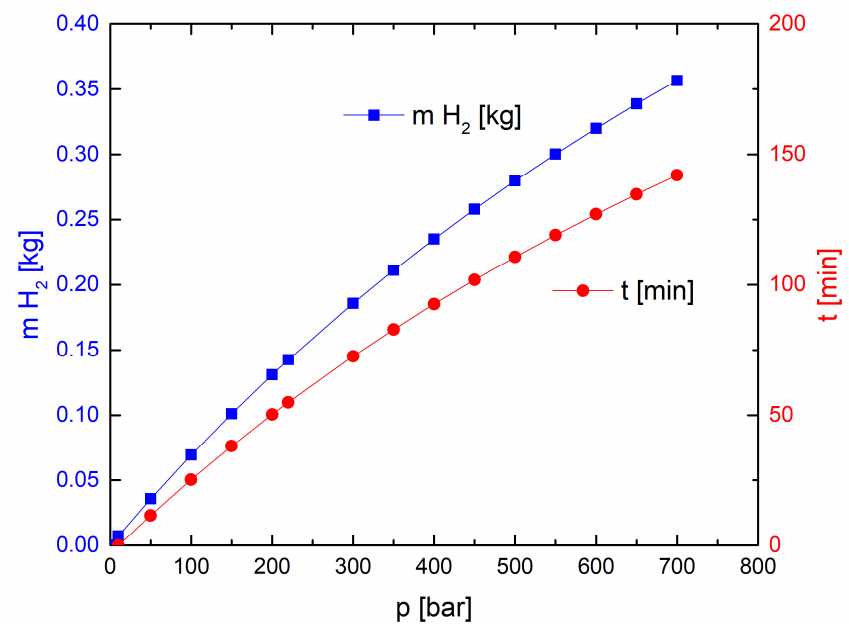

Fig. 2. Changes in hydrogen mass $\left(\mathrm{mH}_{2}\right)$ in a $9-\mathrm{Ndm}^{3}$ composite cylinder depending on compression pressure and predicted operating time of a PEMFC BCH 2000-W stack supplied with hydrogen from a $9-\mathrm{Ndm}^{3}$ tank.

As shown in Fig. 1, the consumption of hydrogen fuel increases along with the expected $\mathrm{P}_{\text {nom }}$ of the PEMFC stack. With the instantaneous increase of the electric power of the PEMFC stack above $\mathrm{P}_{\text {nom, }}$, slight deviations from linearity can be expected due to dynamic changes enforced by the PEMFC stack control system.

Predicted hydrogen consumption (litres/min) at the $\mathrm{P}_{\text {nom }}$ nominal power point is required to estimate the required amount of hydrogen fuel to be stored in the lightweight composite tank for a planned UAV mission. The amount of stored hydrogen fuel significantly impacts the operating time of the PEMFC stack, which in turn may directly influence the estimated time of flight.

When pressure methods are used for the storage of hydrogen fuel, the amount of fuel to be stored depends on the compression pressure.

Calculation of the mass of stored hydrogen $\left(\mathrm{mH}_{2}\right)$ depending on the compression pressure was based on the Clapeyron equation, modified by the compressibility factor: 


$$
p V=z n R T
$$

where $\mathrm{p}$ - pressure [bar], $\mathrm{V}$ - gas volume $\left[\mathrm{dm}^{3}\right], \mathrm{z}$ - compressibility factor in given pressure and temperature conditions (at temperatures of $300 \mathrm{~K}$, according to [57]), $\mathrm{n}$ - amount of gas [mol], $\mathrm{R}$ - universal gas constant $[\mathrm{J} / \mathrm{mol} \mathrm{K}] \mathrm{R}=8.314 \mathrm{~J} /(\mathrm{mol} \cdot \mathrm{K}), \mathrm{T}-$ temperature $[\mathrm{K}]$.

Fig. 2 shows the relationship between variations in hydrogen mass $\mathrm{mH}_{2}$, compression pressure, and predicted operating time (t) of a BCH 2000-W FC stack at nominal power $\mathrm{P}_{\text {nom. }}$. Based on Fig. 2, it can be said that the operating time of the BCH 2000-W FC stack at standard hydrogen compression pressures permissible in Poland (approximately 200 bar) will equate to approximately $1 \mathrm{~h}$. In order to extend the operating time of the FC generator, hydrogen must be stored under higher pressures, i.e. approximately 300-400 bar, by means of additional pressure boosters.

The amount of hydrogen stored prior to initiating operation of the FC generator and its changes during operation under variable loads should be monitored by the generator's monitoring, measurement, and control systems.

\subsection{Analysis of hydrogen fuel consumption for the generation of electric power and purging of a PEMFC stack}

Fig. 3 shows changes in current $(\mathrm{I})$, voltage $(\mathrm{U})$, power $(\mathrm{P})$, and hydrogen volume (V) during operation of the $\mathrm{BCH} 2000-\mathrm{W}$ FC generator.

The experimental data relates to the $\mathrm{BCH} 2000-\mathrm{W}$ FC stack while it was being loaded with various current (I) values ranging from 0 to 60 A, i.e. from start-up to an electrical load corresponding to the nominal power $\mathrm{P}_{\text {nom. }}$.

The consumption of hydrogen fuel in PEMFC stacks is related to electric power generation (direct conversion of the chemical energy of fuel into electrical energy) and to purging of the FC anode. As mentioned previously, during the operation of a FC stack, water is also released; this water, when deposited in the anode material, blocks the fuel supply by limiting the electrochemical reaction zone of hydrogen fuel oxidation and thus the production of electric power. In addition, nitrogen, which is a component of the supply of air, can also penetrate into the anode space and reduce the efficiency of the reaction

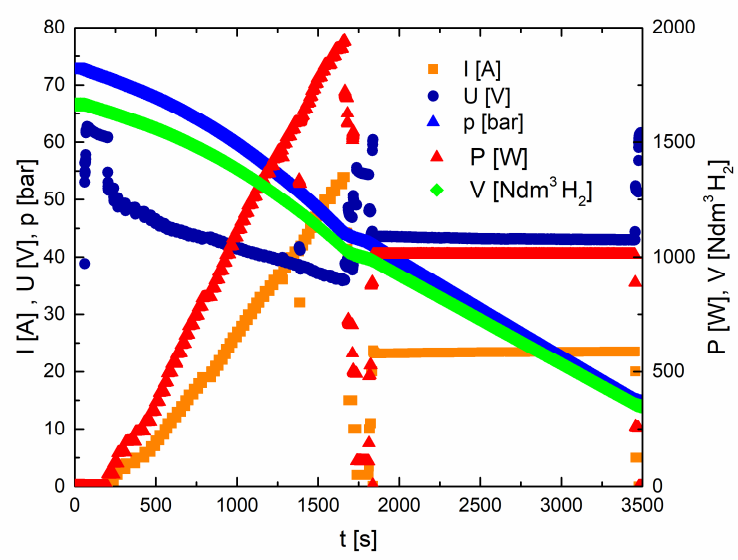

Fig. 3. Variations in current $(\mathrm{I})$, voltage $(\mathrm{U})$, electric power $(\mathrm{P})$, pressure $(\mathrm{p})$, and hydrogen volume (V) during the operating time ( $\mathrm{t}$ ) of a BCH 2000-W FC stack under variable electric load 
In the course of these tests, based on changes in the volume of hydrogen (determined on the basis of changes in hydrogen pressure $\mathrm{p}_{\text {bar }}$ with the use of an AST20HA electronic pressure sensor), analysis of hydrogen fuel consumption for the generation of electric power $\mathrm{P}_{\text {nom }}$ and the purging process controlled by the solenoid valve was carried out. The operation of the solenoid valve was controlled by accounting for opening of the valve during the operation of the FC stack and the duration of a single opening in one cycle.

Fig. 4 presents the relationship between the hydrogen utilisation rate $\mathrm{q}$ used for the generation of electric power of the $\mathrm{BCH} 2000-\mathrm{W}$ FC stack and the current (I) acquired from the stack.

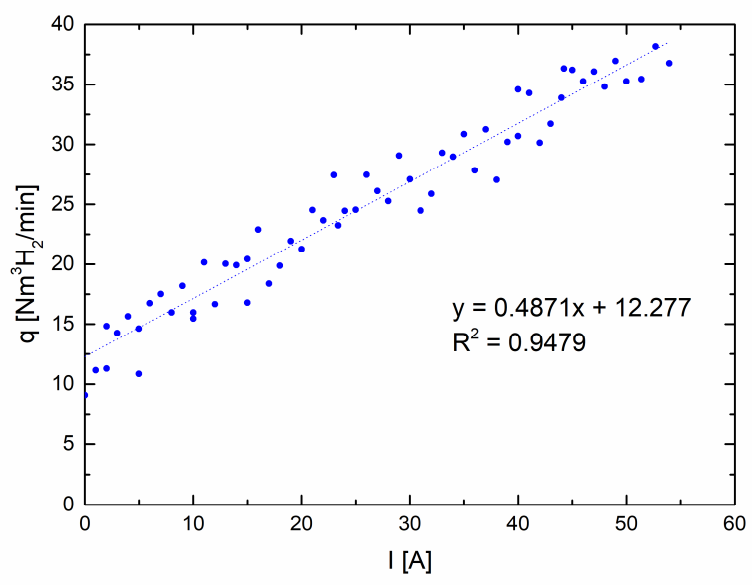

Fig. 4. Variation between the hydrogen utilisation rate $\mathrm{q}\left[\mathrm{Ndm}^{3} \mathrm{H}_{2} / \mathrm{min}\right]$ and current load of the FC stack

Fig. 4 shows the variation between the hydrogen utilisation rate $\mathrm{q}\left[\mathrm{Ndm}^{3} \mathrm{H}_{2} / \mathrm{min}\right]$ used for the generation of electric power and the current drawn from the BCH 2000-W FC stack. The measurement data in Fig. 4 was used to determine this relationship. Based on the adjustment to the linear regression measurement data, $\mathrm{q}=0.49 * \mathrm{I}+12.28$, the dependence of the hydrogen flow on the current (I) generated by the BCH 2000-W FC stack was determined.

Based on the obtained equation, it was found that an average hydrogen flow of 12.3 $\mathrm{Ndm}^{3} \mathrm{H}_{2} /$ min was used to purge the anode side of moisture during operation of the solenoid purge valve regardless of the load on the FC stack. This information is required to determine the real efficiency of the conversion of hydrogen chemical energy into operating electrical energy and the projected real operating time of the fuel cell for the production of electric power, as well as to obtain the additional information necessary to estimate the amount of hydrogen required to power the auxiliaries of the total amount of stored hydrogen fuel.

\subsection{Control of the degree of membrane humidification in the PEMFC stack}

During the operation of the PEMFC stack, in addition to control of the basic electrical parameters of the stack, such as voltage (U), current (I), electric power generated by the PEMFCs (electric power net generation) and energy consumed by monitoring and measurement devices (as parts of the auxiliaries of the FC generator), the degree of humidification in the stack is an important factor [14,15]

One of the methods of humidification is based on a short circuit unit (SCU), an electronic system enabling short-term shortening of the terminals of an FC stack. Its basic 
purpose is to produce water inside the fuel cell as a result of the electrochemical reaction related to the short-circuit current flow. This process enables maintenance of the electrolyte's optimal humidity, which is especially important in the case of open cathode cells that are air-cooled during operation with dry hydrogen gas stored under pressure in a composite tank [16].

Fig. 5a, b shows examples of changes in the PEMFC stack's voltage with and without the SCU system. Fig. 5 shows a decrease in voltage (U) close to 0, repeated at constant intervals. The important parameters here are the time intervals at which the short circuit pulse appears (Fig. 5b, c) and the duration of a single pulse.

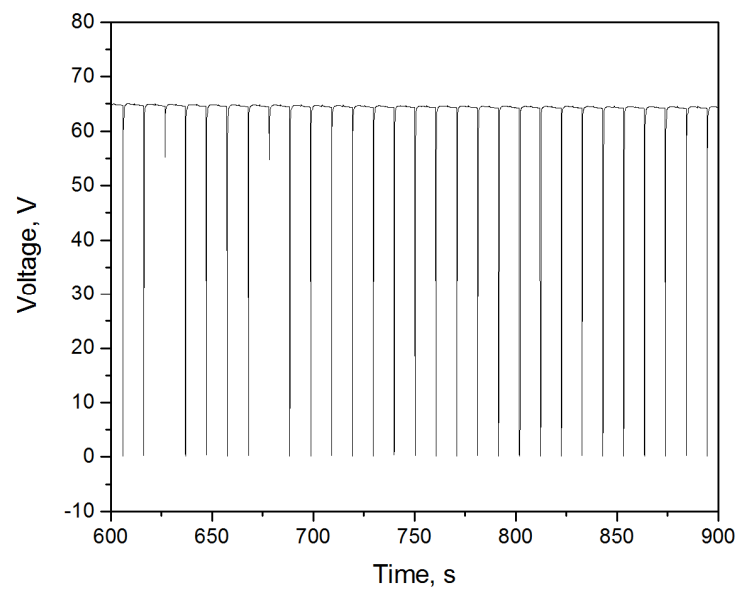

Fig. 5a. Variations in voltage (U) of an FC stack over time (t)
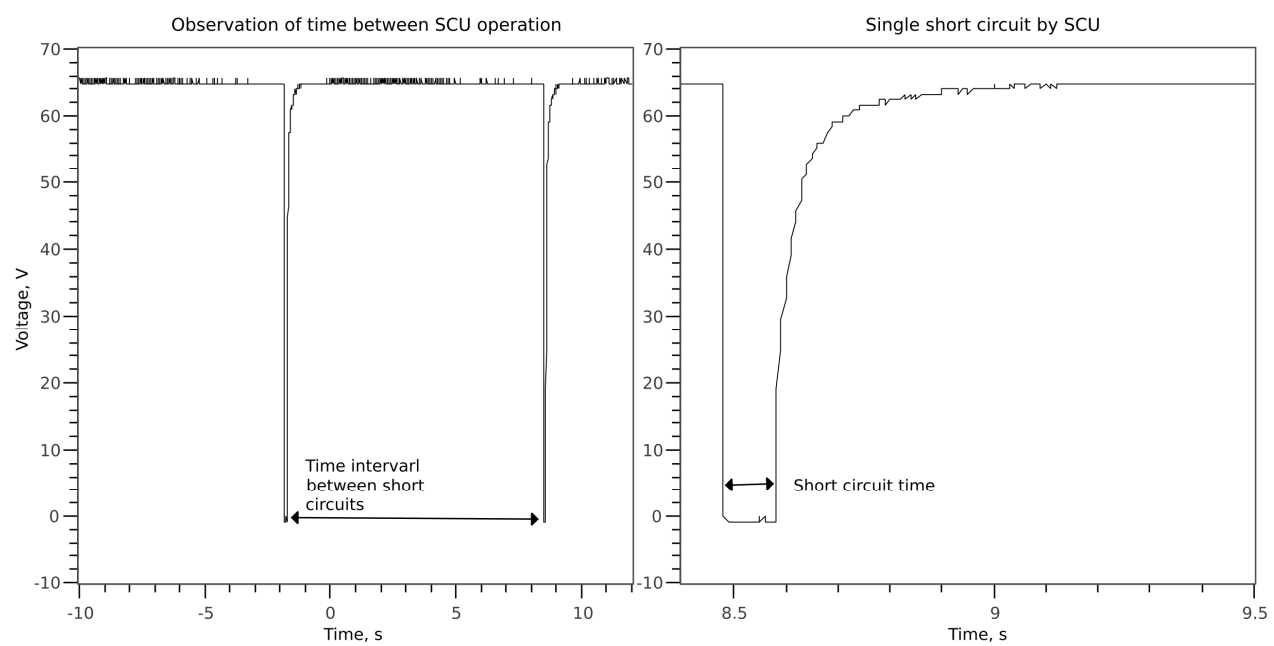

Fig. 5b, c. Changes in the voltage of a PEMFC stack over time (t) with an operating SCU system: a) changes in voltage over time between two consecutive short circuits; b) changes in voltage during a single short circuit

During the operation of the SCU system, which consists of a short-term controlled short circuit of the FC stack, short-term voltage decay, which may affect the operation of circuits consuming electric power (voltage converter, battery pack, electric motor), is immediately observed; this must be taken into account in the design of the control system. It is especially 
important if the powered object requires a continuous power supply, which is the case with UAV applications.

Fig. 6 presents a sample graph of the maximum short circuit current flowing through the SCU system, measured while loading the stack with a current of $38 \mathrm{~A}$.
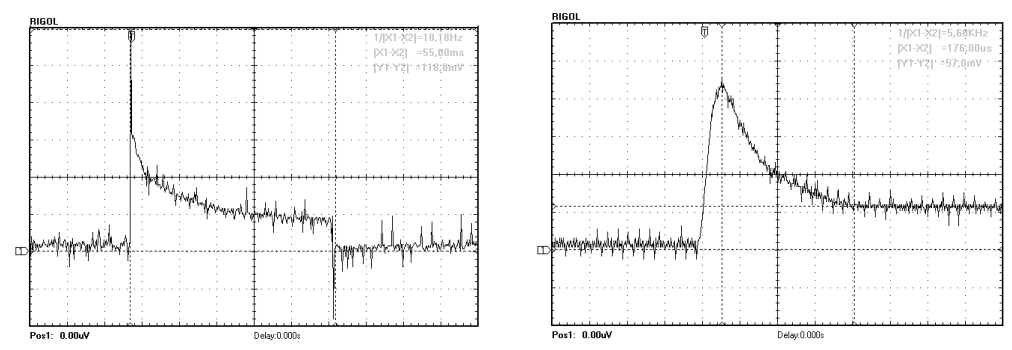

Fig. 6. Current values during 'flowing short-circuit peak' through the SCU system measured while loading the stack with a current of $38 \mathrm{~A}$ (on the left: the whole curve; on the right: focus on the initial short-circuit peak).

Based on Fig. 6, it can be observed that in the case of a short-circuit current forced by the SCU system regularly every $10 \mathrm{~s}$ and lasting for approximately $55 \mathrm{~ms}$, the current reaches approximately $2,140 \mathrm{~A}$ in $28.4 \mathrm{~ms}$, stabilising to approximately $570 \mathrm{~A}$ after $176 \mathrm{~ms}$.

The SCU system must enable the flow of such large currents and the dissipation of the short-circuit energy in the form of heat through the actuating system in the SCU. 'Current peaks' of $2 \mathrm{kA}$ and rapid accumulation occurring during SCU activation may also introduce inductive interference into the monitoring and measurement systems; this should be taken into account in the design of the drone's electrical and electronic system.

\subsection{Development of assumptions for the implementation of monitoring/ measurement and control systems in a 2-kW PEMFC stack}

The implementation of control and monitoring systems in a 2-kW FC stack was based on the adoption of the following assumptions:

The PEMFC stack consists of 60 individual PEMFCs connected in series, with the following electrical parameters:

- Voltage range during operation: 60 to $25 \mathrm{~V}$

- $\quad$ Current (I) range: 0 to $90 \mathrm{~A}$

- $\quad$ Electric power range from 0 to $2500 \mathrm{~W}$

- Temperature measurement range T1-T8; maximum permissible operating temperature $\mathrm{T}_{\max }-65^{\circ} \mathrm{C}$

Fig. 7 presents a schematic diagram of the operation of the FC stack controller; Figs. 8, 9 present descriptions of the basic algorithms of the control system.

The controller represented by the schematic diagram shown in Fig. 7 operates according to the algorithm shown in Figs. 8, 9. It controls the operation of the $\mathrm{H}_{2 \text { in }}$ valve, which in turn controls the supply of hydrogen during operation of the FC stack under a variable current load. When the FC stack is switched off or a state of emergency arises, it cuts off the supply of hydrogen fuel to the device.

The $\mathrm{H}_{2 \text { out }}$ purge valve installed at the FC stack's hydrogen outlet is used to purge the anode space during start-up of the stack and during its operation by opening frequently. The important parameters are the valve's opening frequency during operation and the duration of a single opening during the purging cycle. 
The $\mathrm{W}$ switch is used to connect/disconnect the load to/from the FC stack during the start-up procedure and when the permissible parameters of operation of the FC stack have been exceeded.

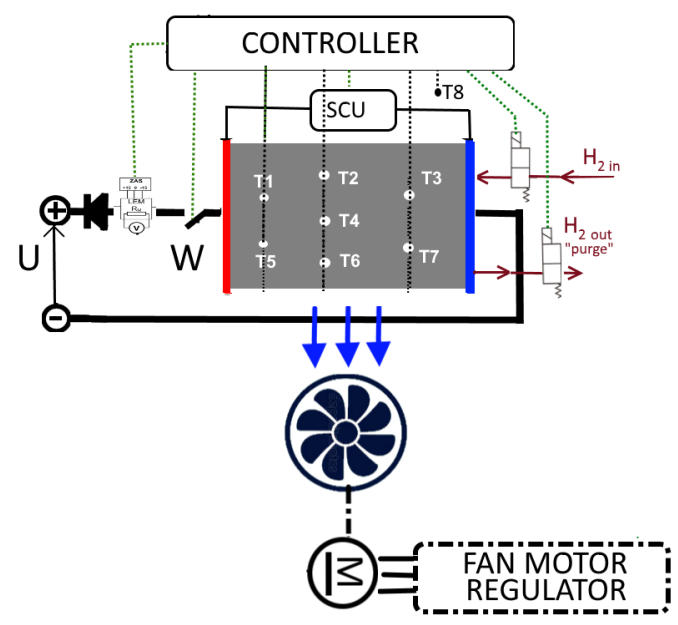

Fig. 7. Diagram of a control system for the operation of a 2-kW PEMFC stack

The control system monitors the voltage (U) and, by means of the current transducer monitors, current (I) drawn by the electrical load connected to the FC stack during its operation. When the limit values $\mathrm{U}<30 \mathrm{~V}$ and $\mathrm{I}>65 \mathrm{~A}$ are exceeded, the load of the FC stack is disconnected by the $\mathrm{W}$ switch.

The temperature of the FC stack is monitored by the T1-T8 temperature sensors at all times during operation. The temperature is maintained at $45^{\circ} \mathrm{C}<\mathrm{T}<65^{\circ} \mathrm{C}$ by means of a PWM signal sent from the controller to the speed controller of the cooling fan's electric motors. If the controller detects a temperature in excess of $65^{\circ} \mathrm{C}$, the electrical load is disconnected and the FC stack is switched off, with the exception that cooling may only be switched off when the stack temperature falls below $45^{\circ} \mathrm{C}$.

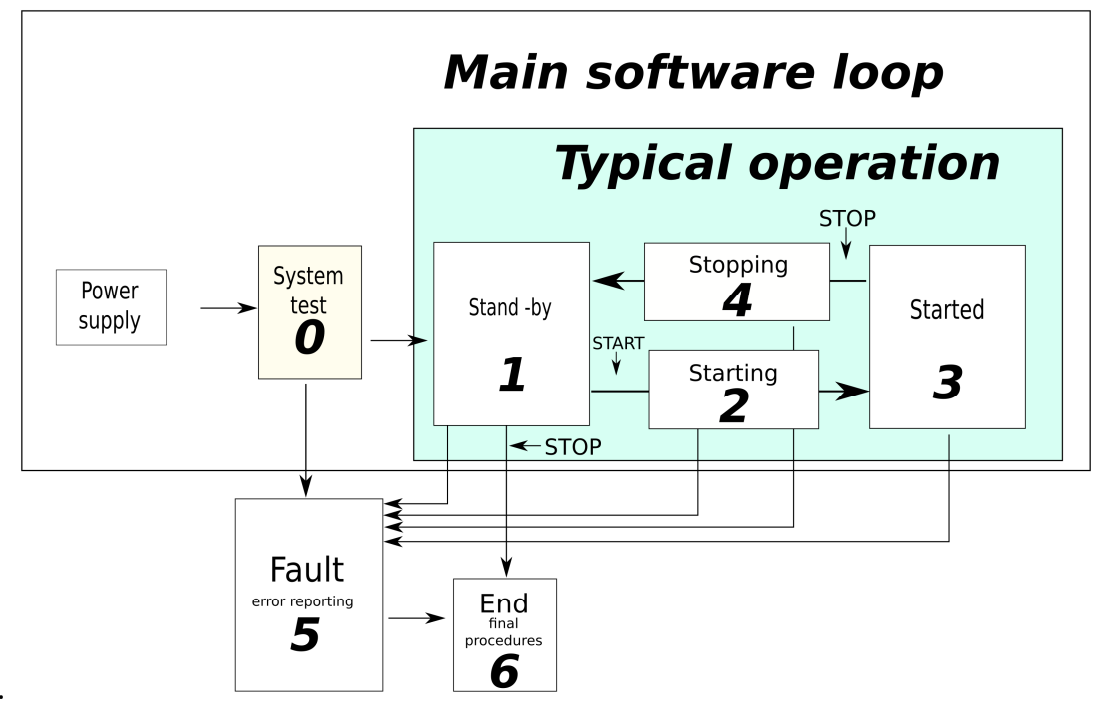

Fig. 8. Diagram of the FC controller software loop

Fig. 8 shows a sample diagram of the PEMFC stack controller software loop. 
During normal operation of the FC stack, the controller monitors the operation of the SCU system used to humidify the stack. The controller also performs a start-up procedure combined with testing of the monitoring and measurement systems as well as the normal and emergency stop and switch-off procedures for the FC stack

Fig. 9a presents short descriptions of the procedures executed by the controller during individual operational states..
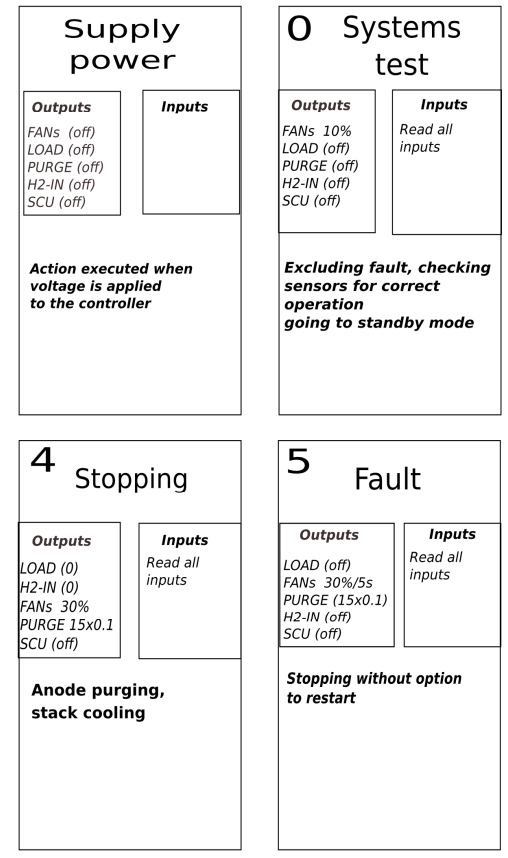
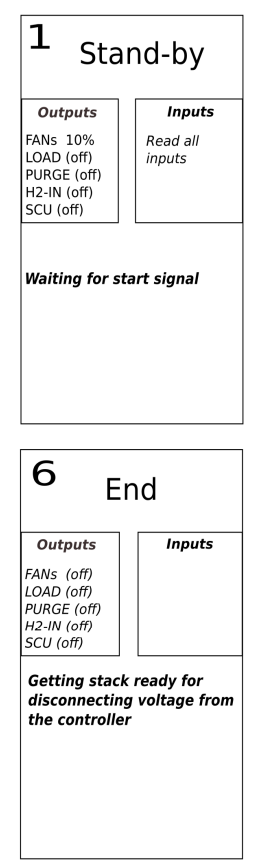
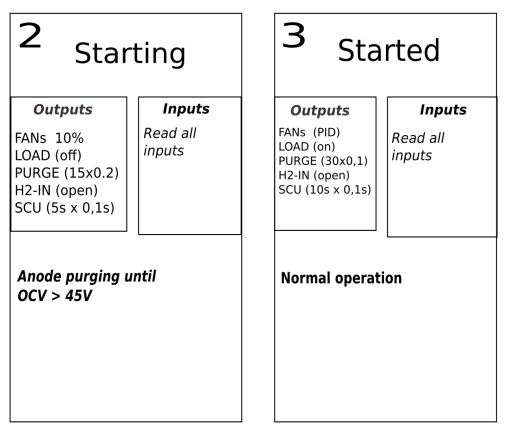

\begin{tabular}{l}
\hline \multicolumn{1}{|c|}{ Alarms } \\
\hline Umin < Stack voltage < Umax \\
Min < Stack current < Imax \\
Tmin < Stack temp. < Tmax \\
Pmin < P H2 <Pmax \\
Two-stage alarms: \\
1- warrning levels \\
2- critical levels \\
\end{tabular}

Fig. 9a. Diagram of the operation of individual components of the FC stack control algorithm

Fig. 9b shows a description of individual signals fed and generated by the FC stack control algorithm

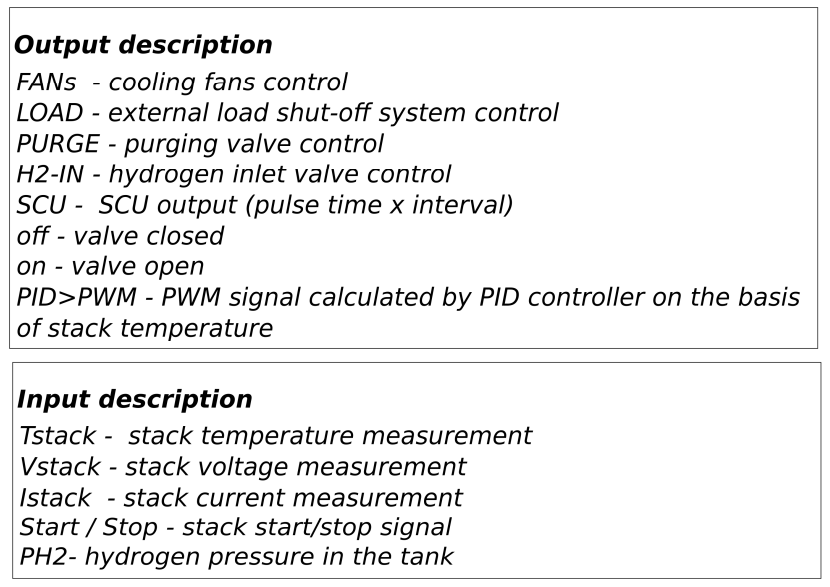

Fig. 9b. Description of individual signals in the PEMFC stack operating algorithm 


\section{Summary}

The study presents the methodology used to obtain the experimental data required to develop monitoring and measurement systems for energy generators with low-temperature proton-exchange membrane fuel cells. The method of analysis of changes in electrical parameters such as voltage, current, and power generated by an FC stack and collected by the FC generator's auxiliary devices was presented in order to develop algorithms for controlling the operating parameters of the power unit. The methodology to be used to estimate the amount of hydrogen required to ensure continuous operation of the FC stack with the specified nominal power was proposed. Analysis of consumption of hydrogen fuel for electric power generation and purging was carried out. The method of humidifying the PEMFC stack by means of the SCU system was described. The duration of a pulse and intervals between pulses and their impact on the operation of the drive unit was analysed. The proposed control algorithm was presented, along with a description of the individual functions of the FC generator monitoring and measurement systems.

The study was carried out with the support of the National Centre for Research and Development (NCBR) POIR.01.01.01-00-0682/17 'Increasing flight duration of unmanned aerial vehicle (UAV) and UVAS by using hybrid energy sources' financed in 2017-18.

\section{References}

1. T.Q. Hua, R.K. Ahluwalia, J.-K. Peng, M. Kromer, S. Lasher, K. McKenney, K. Law, J. Sinha Int. J. Hydrogen Energ. 36, 3037 (2011)

2. M. Afzal, R. Mane, P Sharma, Int. J. Hydrogen Energ. 42, 30661 (2017)

3. T.A. Semelsberger, K.P. Brooks, J. Power Sources 279, 593 (2015)

4. B. Becker, G.W. Mair, Int. J. Hydrogen Energ. 42, 13810 (2017)

5. L.Wang, Ch. Zheng, Sh. Wei, B. Wang, Z. Wei, Int. J. Hydrogen Energ. 40, 6853 (2015)

6. Ch. He, R. Yu, H. Sun, Z. Chen, Int. J. Hydrogen Energ. 41, 15821 (2016)

7. S. Mellouli, E. Abhilash, F. Askri, S. B. Nasrallah, Appl. Therm. Eng. 102, 1185 (2016)

8. E. Stamatakis, E. Zoulias, G. Tzamalis, Z Massina, V Analytis, Ch. Christodoulou, A Stubos, Renew. Energ. 127, 850 (2018)

9. H. Oguchi, E.J. Heilweil, D. Josell, L.A. Bendersky, J. Alloy. Compd. 477, 8 (2009)

10. W. Chen, L.Z. Ouyang, J.W. Liu, X.D. Yao, H. Wang, Z.W. Liu, M. Zhu, J. Power Sources 359, 400 (2017)

11. M. Monteverde, L. Magistri, Int. J. Hydrogen Energ. 37, 5452 (2012)

12. T. Kim, S. Kwon, Int. J. Hydrogen Energ. 37, 615 (2012)

13. B.H. Liu, Z.P. Li, S. Suda, J. Alloy. Compd. 468, 493 (2009)

14. X. Guo, Z.Shao, Y. Xiao, Y. Zeng, S.Liu, X. Wang, B. Yi, Electrochem. Commun. 44, 16 (2014)

15. W. Vielstich, A. Lamm Handbook of Fuel Cells: Fundamentals, Technology, Applications, vol. 4, John Wiley \& Sons, 2003

16. Y. Zhan, Y. Guo. J. Zhu, J. Power Sources 270, 183 (2014) 